Asian Social Work Journal (ASWJ), Volume 6, Issue 2, (page 1 - 8), 2021

DOI: https://doi.org/10.47405/aswj.v6i2.164

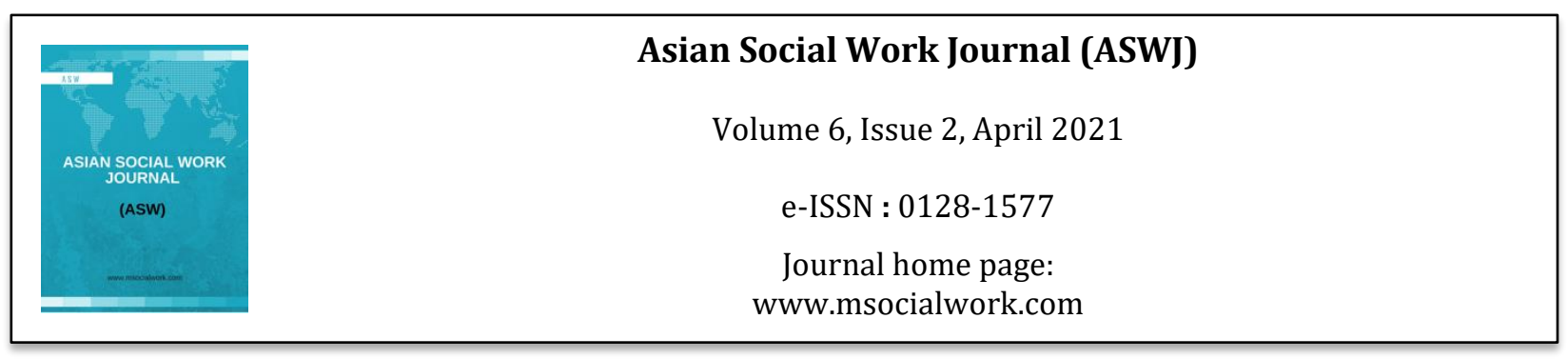

\title{
Children's Health and Well-being during the COVID-19 Pandemic in Japan
}

\author{
Naoki Nakamura ${ }^{1}$ \\ 1Department of International and Regional Studies, Faculty of Education, \\ Hokkaido University of Education, Japan
}

Correspondence: Naoki Nakamura (nakamura.naoki@h.hokkyodai.ac.jp)

\begin{abstract}
The COVID-19 has caused challenges at all levels of society. It is necessary to, while carefully looking at impact that COVID-19 will have on children's health and well-being, and to steadily implement social work services accordingly. This paper highlights some key challenges and concerns for health and wellbeing on children and adolescents in Japan during COVID-19 pandemic. The purpose of this paper is to consider how the COVID-19 pandemic and the policy taken to mitigating the risk of COVID-19 have impacted children in Japan. In conclusion, we are not saying that COVID-19 policy responses such as school closures overall are ineffective for mitigating the COVID-19 pandemic in Japan. However, as we have seen, school closing policy is likely to have a negative impact on children's health and well-being such as increased risks of mental health, abuse and suicide. The important point is that these impacts is not the impact of COVID-19 but the impact of the policy responses to COVID-19. The policy responses are likely to lead to a range of unexpected impacts and results. Therefore, policy makers, social workers and other professionals always should consider for the impact of policy responses to COVID-19 on children and adolescents.
\end{abstract}

Keywords: children and adolescents, COVID-19, School closure

\section{Introduction}

COVID-19 has spread around the world. As of April 2021, Japan is concerned that COVID-19 are driving a nascent fourth wave in the pandemic. COVID-19 causes various challenges all over the world. Most of us would accept that children's health and well-being during the COVID-19 pandemic is a growing problem. Japanese society also has been facing with several challenges regarding children's health and well-being during the COVID-19 pandemic as described later.

The impact of COVID-19 pandemic and the impact of the policy responses such as restrictions to the movement of people causes change to people's health and well-being. This paper examines the impact that it has on children's health and well-being and the provision of social work services. The COVID-19 pandemic is causing significant risk to health and well-being on children and adolescents. According to Witt, school closures have led to distance-learning and home-schooling - not to mention challenges to food distribution: school is the place where many children around the globe get a consistent daily caloric intake. School-based nutrition is a reality in both developing and developed countries (Witt et al, 2020). Witt discussed parents are experiencing increased pressure to work from home, to keep jobs and businesses running, as well as to support, educate and comfort their children at the same time (Witt et al, 2020). Beside worries and anxieties related to COVID-19, the economic situation has worsened with 
Asian Social Work Journal (ASWJ), Volume 6, Issue 2, (page 1 - 8), 2021

DOI: https://doi.org/10.47405/aswj.v6i2.164

high and rising levels of unemployment in all affected countries. Fegert discussed this has put a lot of pressure on children, adolescents and their families which could result in distress, mental health problems and violence (Fegert et al, 2020). Araújo discussed COVID-19 produce potential risks to child development due to the risk of illness, protective confinement, social isolation, and the increased stress level of parents and caregivers (Araújo et al, 2020). And Araújo suggests, this situation becomes an adverse childhood experience (ACEs) and may generate toxic stress, with consequent potential losses for brain development, individual and collective health, and the long-term impairment of cognition, mental and physical health, and working capacity of future adults (Araújo et al, 2020).

However, there are scarce data about the impact of pandemics on children's health and well-being. To protect children's health and well-being during the COVID-19 pandemics, it is necessary to consider the challenges facing children and adolescents. This paper highlights some key challenges and concerns for health and well-being on children and adolescents in Japan during the COVID-19 pandemic. The purpose of this paper is to consider how the COVID-19 pandemic and the policy taken to mitigating the risk of COVID-19 have impacted children in Japan. To this end, we have searched and used the wide range of literature review and data collection related to health and well-being during the pandemic. This study to improve the understanding of the impact of COVID-19 pandemic on children's health and well-being can help to social workers and other professionals, because guide strategies to prevent damage to child and family and promote positive child development.

\section{The Social Impact of the COVID-19 Pandemic}

The COVID-19 has caused challenges at all levels of society. It is necessary to, while carefully looking at impacts that COVID-19 will have on society — such as health, well-being and others - and to steadily implement social work services accordingly.

As Lustig \& Tommasi suggests, the most vulnerable segments of society, especially those living in extreme poverty, are being hit the hardest by the COVID-19 pandemic (Lustig \& Tommasi, 2020). According to the Lancet, the COVID-19 pandemic, vulnerable groups are not only elderly people, those with ill health and comorbidities, or homeless or underhoused people, but also people from a gradient of socioeconomic groups that might struggle to cope financially, mentally, or physically with the crisis (Lancet, 2020). More noteworthy is a person not considered vulnerable at the outset of a pandemic can become vulnerable depending on the policy response. The risks of sudden loss of income or access to social support have consequences that are difficult to estimate and constitute a challenge in identifying all those who might become vulnerable (Lancet, 2020). From this perspective, paying special attention to these poor people and vulnerable people in the policy response and social work service is crucial.

There is also concern that the impact of the policy responses to COVID-19 on children and adolescents Consider school closures for example. According to the Food and Agriculture Organization of the United Nations (FAO), on March, 2020, among the measures taken by the governments of many countries in Latin America and the Caribbean in the face of the rapid expansion of the COVID-19 is the closure of schools and, therefore, the suspension of school feeding programs. These programs currently benefit 85 million children in Latin America and the Caribbean. For about 10 million, they constitute one of the most reliable daily sources of food. FAO discussed the suspension of school feeding programs will pose a challenge to the food security and nutritional status of many children, especially those from the most vulnerable groups (FAO, 2020).

We know from past crisis that there can be linkages between anxiety and depression and viral diseases such as Influenza A (H1N1) (Witt et al, 2020). And, UN reported Ebola virus disease outbreak had implications for children in Africa. It has been reported that there is a concern that girls are at greater risk of sexual abuse and socio-economic impacts of the Ebola virus disease on Africa pregnancy and marriage due to the loss of education and career opportunities, and greater poverty (UN, 2015). We believe the current crisis is likely to have a similar impact on the health and well-being of children and adolescents. 
Asian Social Work Journal (ASWJ), Volume 6, Issue 2, (page 1 - 8), 2021

DOI: https://doi.org/10.47405/aswj.v6i2.164

As we have seen, recent studies emphasized the impact that the COVID-19 pandemic can have on children and adolescents. Circumstances such as child malnutrition, abuse, and adverse childhood experience (ACEs) occurring at early stages in life, often have negative impact. More noteworthy is, in socioeconomically vulnerable settings, depending on the COVID-19 policy responses can worsen children's health and well-being. Therefore, we need to carefully consider the negative impact of COVID-19 and the impact of the policy response on children.

As we said in the introduction, this paper we look at how the pandemic and the policy taken to mitigating the risk of COVID-19 have impacted children and adolescents in Japan. There is room for further discovery and discussion about the impact of the policy responses to COVID-19 on children and adolescents. By actually collecting and examining various data and literature review related to health and well-being during the pandemic, we were able to find them. This will be detailed in the following section.

\section{The impact of COVID-19 on children's lives in Japan}

As COVID-19 spread around the world, many countries, including Japan, adopt restrictions to the movement of people. In Japan, at the end of February 2020, former Prime Minister Shinzo Abe asked the closure of all elementary schools, junior high schools and high schools nationwide, beginning March 2, 2020. At the same time, he asked on people to stay-at -home and social distancing. According to the education ministry, 98.9\% of schools were closed as of March, 2020. While the school closure was initially introduced as an early spring break, the period was extended as the government declared a nationwide state of emergency over the coronavirus in April. Many schools finally reopened fully between May and June, 2020 (Japan Times, 2021). After schools were reopened in June, the school day was dispersed. It seemed as if the spread of COVID-19 infection is gradually lessening, but then the infection has spread again, Japan is concerned that COVID-19 are driving a nascent fourth wave in the pandemic as of April, 2021. Most of school travels and sports events had been cancelled during COVID19 pandemic. If there is a cluster outbreak in a school, the school is closed for a few days of disinfection (Usami et al, 2020). The COVID-19 policy responses such as school closures, stay-at-home and social distancing could be causing a feeling of insecurity and isolation among children. Japan may be facing with several challenges regarding children's mental health during the COVID-19 pandemic.

\section{Children's Mental Health}

A survey of Japanese children found that many children were feeling stress about the COVID-19 pandemic and the policy response such as school closures and social distancing. According to a survey conducted in Japan through September 1 to 22, 2020 by the National Center for Child Health and Development (NCCHD) to assess, the situation for children during the COVID-19 pandemic, many children felt some kind of stress. $40 \%$ of children feel uncomfortable when thinking of COVID, $30 \%$ gets irritated easily, and $27 \%$ has difficulty concentrating. Moreover, $18 \%$ responded that they can't sleep or wakes up at night and 14\% responded that they often have unpleasant dreams (Figure 1). The additional comments that children gave apart from the multiple-choice responses revealed they had issues at school and home. Some mentioned that "I wish everyone would stop wearing masks at school. I cannot speak my mind because I cannot hear their voice well or see their faces when they're wearing a mask", "I want my teachers to listen to me in a room where I feel safe to talk to them and not be heard by other students", "It's not easy to ask for advice I need someone to help me do that." and "Parents should spend less time on their phones" (NCCHD, 2020). Others said that they are nervous or reluctant about going to school, they are terrified about the potential backlash and bullying that they might face if they become infected. Some said parents were scary as they getting angry quickly (NCCHD, 2021).

\section{Child abuse and neglect}

Children's education has been suffered during the COVID-19 pandemic. Children's school life has been turned completely upside down by the COVID-19 or the policy responses such as school closures. Those are causing a feeling of insecurity and isolation among children. Most of us would accept that the need 
Figure 1: Children's Mental Health

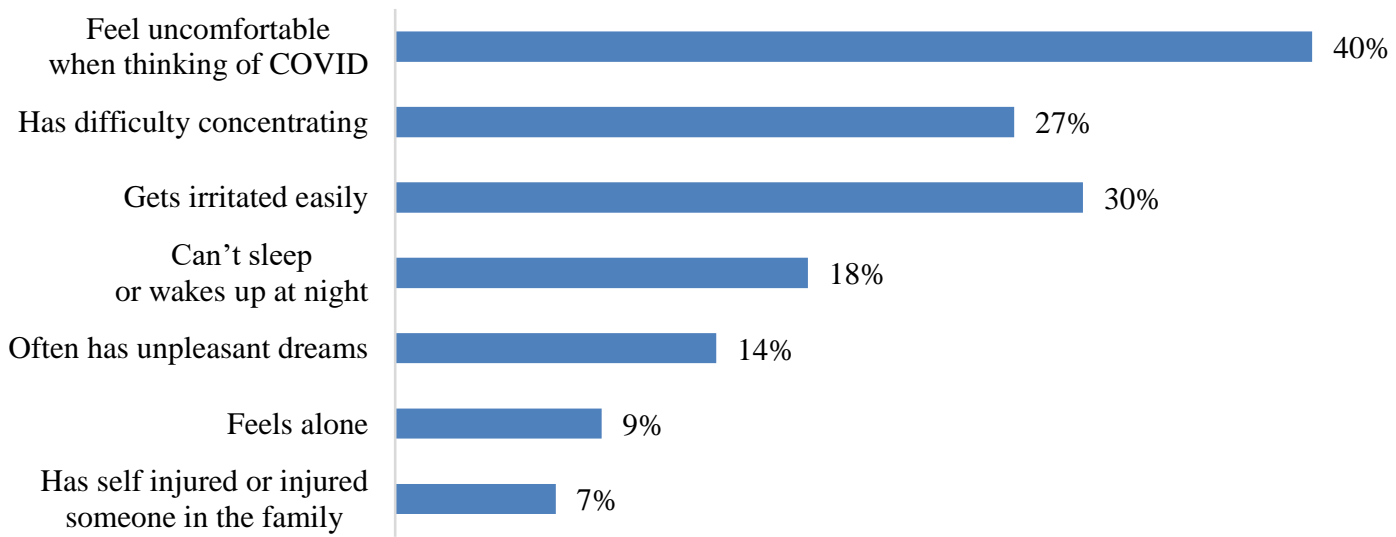

Created by author based on date from NCCHD (2020)

Figure 2: Child abuse under COVID-19 pandemic (Usami et al, 2020)

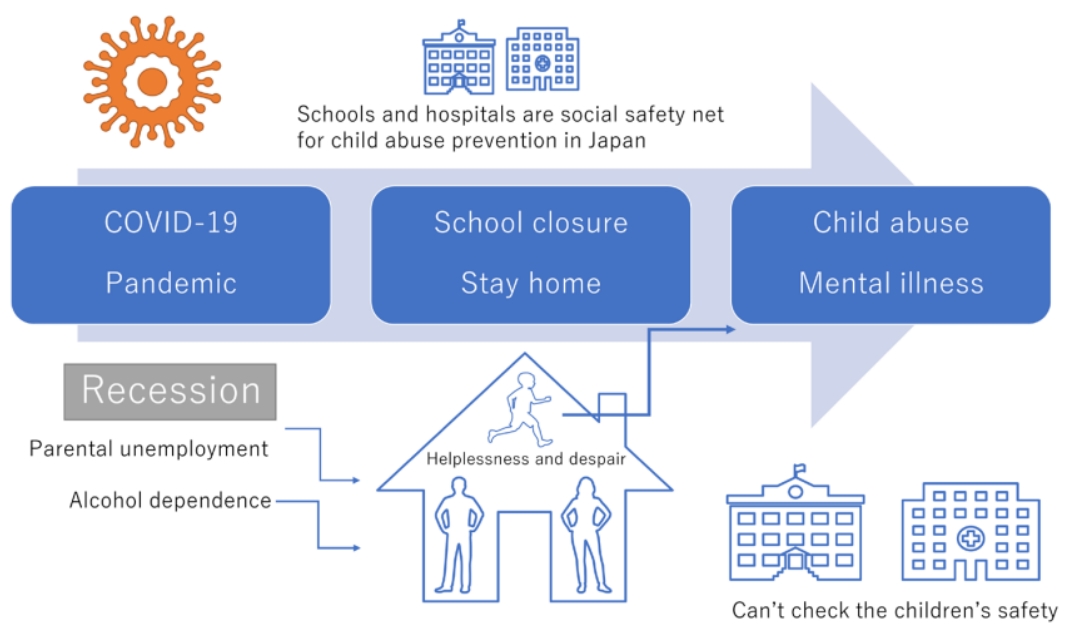

for peer groups is especially high during adolescence. Usami discussed adolescents grow up independent and prioritize peer connections over their parents, which can pose significant challenges to young people's healthy emotional development if it is stifled (Usami et al, 2020). As we saw earlier, many children were feeling stress about the COVID-19 and the policy response. And the stress causes increased mental health problems among children. Most of children could not attend school because of the COVID19 policy responses such as school closures. From the children perspective, it had limited interaction with teachers, peer groups and friends. There is one other Usami pointed out that is important for prevent the repetition of child abuse in the home due to parental unemployment, alcohol problems, and reduced contact with non-family members in stay home and the recession as a result of COVID-19 (Usami et al, 2020). We can see from Figure 2 that the policy for mitigating the COVID-19 pandemic put the child at a higher risk of abuse and neglect (Figure 2).

The number of child abuse and neglect cases handled by child consultation centers across Japan in fiscal 2019 rose by 33,942 from the previous year to 193,780, the number of child abuse and neglect cases has been increasing every year (Figure 3). However, during COVID-19 pandemic, there are unprecedented trend in child abuse and neglect reporting. Comparing 2019 to 2020 by month, the data shows that the monthly date totals of child abuse and neglect reports were $0.7 \%$ lower in May 2020, 3.8\% lower in July and $4.5 \%$ lower in November (Figure 4). 
Asian Social Work Journal (ASWJ), Volume 6, Issue 2, (page 1 - 8), 2021

DOI: https://doi.org/10.47405/aswj.v6i2.164

Figure 3: Changes in number of child abuse and neglect consultations responses at child guidance centers

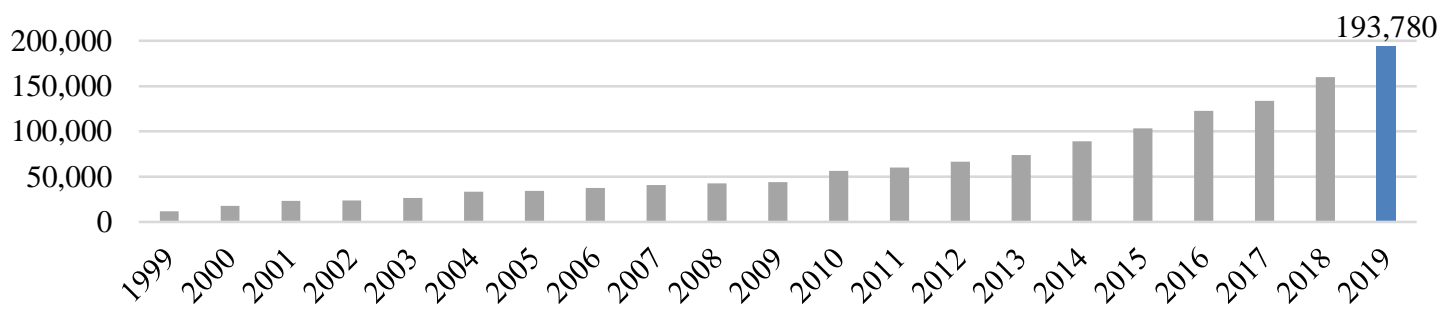

Figure 4: The number of child abuse and neglect consultations responses at child guidance centers in 2020 compared with 2019.

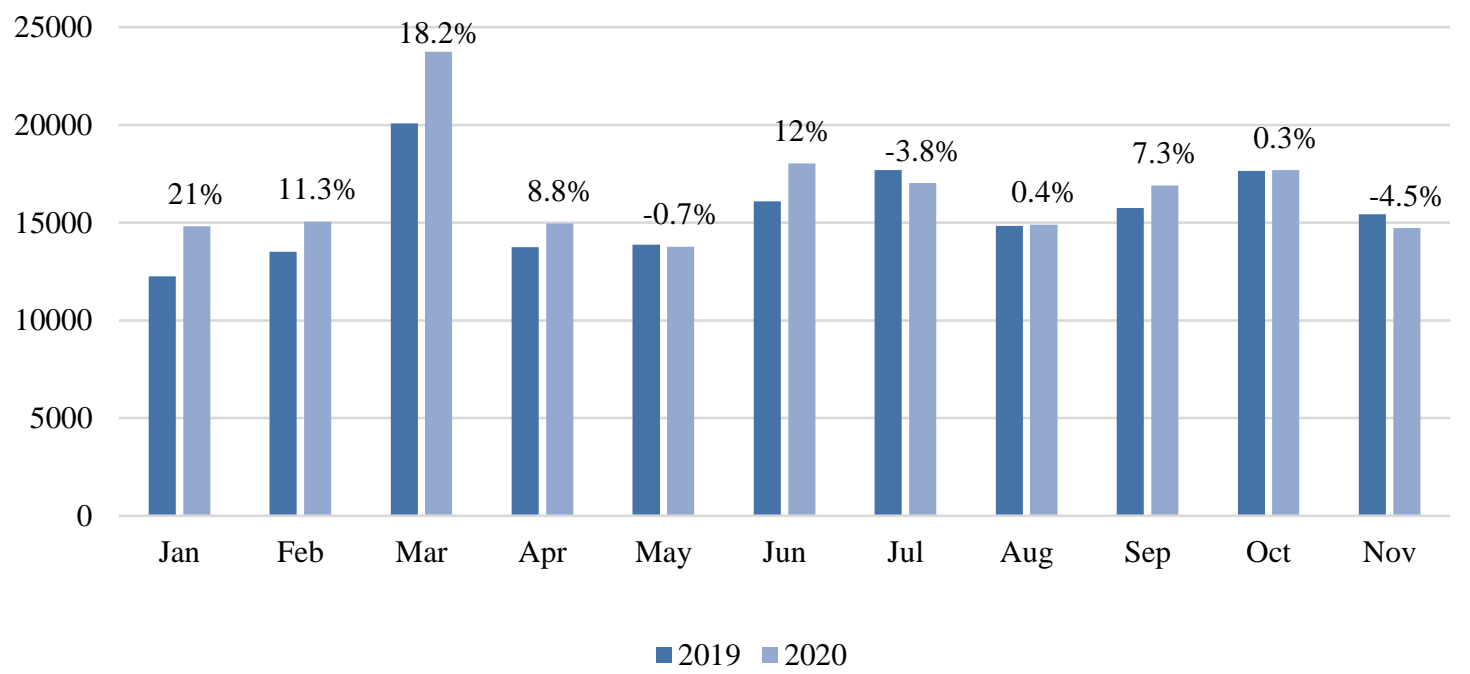

We should notice that a significant drop in reports of child abuse and neglect. As suggested earlier, the pandemic increase the risk for child abuse and neglect. The main reason why increase child abuse and neglect is that child abuse could increase due to prolonged school closures and parents losing their incomes as many people are forced to stay at home amid the outbreak (ASAHI SHIMBUN, 2020). The CIVID-19 may increase child abuse and neglect, but in fact Japan sees drop in reports of child abuse and neglect since the pandemic. What causes a drop in the number of reports of child abuse and neglect during COVID-19 pandemic? One explanation for drop in reports of child abuse and neglect may be that there are many hidden abuse cases. To borrow Baron's expression, it is "suffering in silence" (Baron, Goldstein, Wallace, 2020).Campbell considered this decrease may be a result of fewer opportunities for detection as opposed to an actual decrease in incidence (Campbell, 2020), and Lawson discussed, the rates of reported child abuse and neglect appear to be decreasing during the pandemic as families shelter in place and reduce contact with mandated reporters (Lawson, Piel, Simon, 2020).

The closures of schools and other critical community organizations has limited key community partners in their ability to detect and report abuse (Campbell, 2020). In Japan, 13\% of child abuse and neglect reports come from friends and neighbors and $7.7 \%$ of these reports come from education personnel. Teachers, friends and neighbors could not really meet children in person every day in school or community because schools and communities were closed. We don't know the exact number of the cases, but it is thus possible many cases of child abuse and neglect is going unreported. Another possible explanation is children's relationships and interactions with the important adults is likely have limited by stay-at-home orders. Reporters of child abuse and neglect such as police personnel, pediatricians, and extended family members may be difficult to recognizing and reporting abused children during COVID- 


\section{Asian Social Work Journal (ASWJ), Volume 6, Issue 2, (page 1 - 8), 2021 DOI: https://doi.org/10.47405/aswj.v6i2.164}

19 pandemic because the pandemic is reducing opportunities to meet important adults other than family members.

The underreporting of child abuse has not been a factor in discussions about school closures and stay-athome initially. However, now, most of us would accepted that when closing schools and stay-at-home, cases of child abuse and neglect are more likely to go unnoticed and unreported. school closures and stay-at-home may be effective for mitigating the COVID-19 pandemic, but policymakers should consider the under-reporting of child abuse and neglect.

\section{Suicide}

Lastly, we consider school-age suicides. It is important to notice that school reopening may cause schoolage suicides. School-age suicides has been rapidly increasing after the school reopens, $41 \%$ on year to record 479, this according to the Ministry of Education, Culture, Sports, Science and Technology (MEXT). It's the highest figure since data tracking began in 1978 (Figure 5). From 2019 to 2020, schoolage suicides increased by 8 persons in elementary school students, increased by 40 persons in junior high school students, and increased by 92 persons in high school students.

We can see in Figure 5 that it looks like a mountain range where two peaks are visible. The school-age suicides were concentrated in June and after August, 2020. Schools around Japan in-person learning began again on June 1 after being closed for three months to prevent covid-19 outbreaks and clusters among school children. Then in August, many schools started the second semester, after summer break - schools brought the start of second semester forward from September to August because make up for school closures in April and May.

Though the reasons for that increase in school-age suicide are not completely clear, Japan Times reported the key reasons cited for suicides remained the same as other years, such as worries over future choices, weak academic performance and bad relationships with parents, but an increase was seen in the number of suicide cases related to mental disorders and depression (Japan Times, 2021).

According to a survey by the National Center for Child Health and Development (NCCHD, 2021) found that $30 \%$ of the 344 high school students surveyed had experienced symptoms of moderate to severe depression due to the pandemic - this survey carried out in November and December 2020, when the number of COVID-19 cases increased. Additionally, such symptoms were also found in $15 \%$ of the 261 elementary school students and $24 \%$ of the 110 junior high school students surveyed. It is therefore possible that the COVID-19 pandemic or the policy responses to COVID-19 might be one of the causes school-age suicides.

Figure 5: The number of elementary, junior high and high school students who killed themselves in Japan

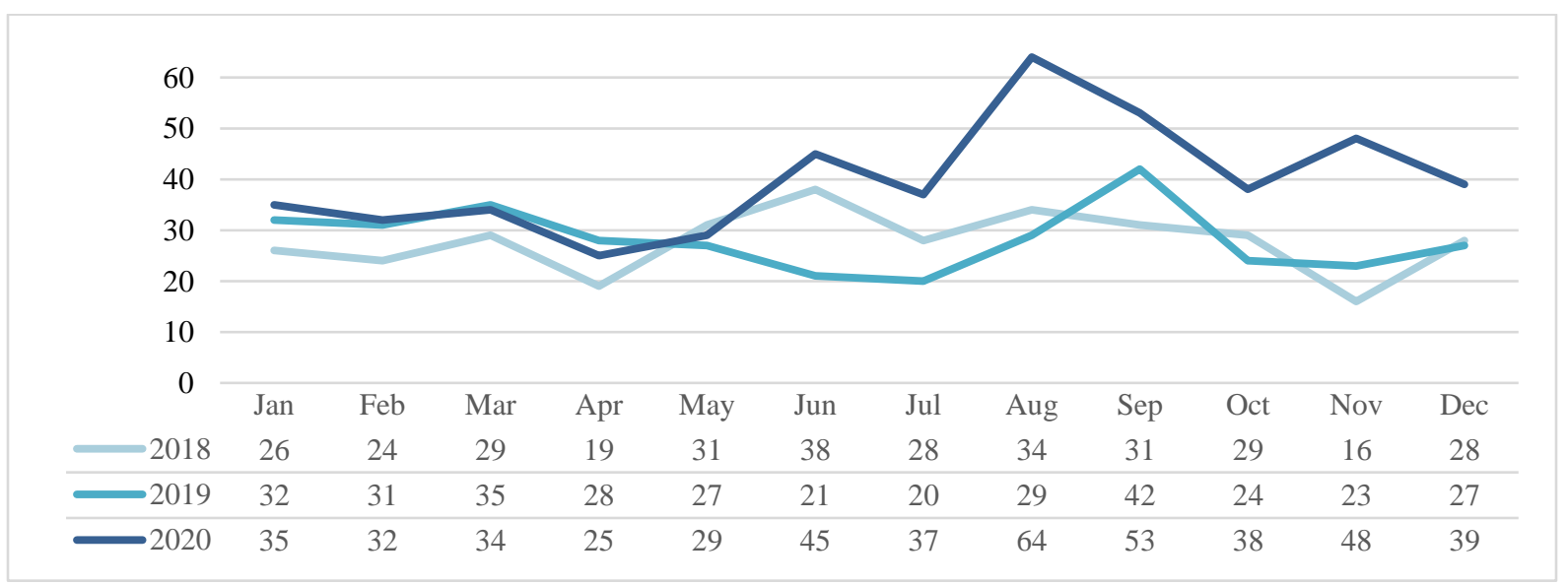

Created by author based on date from MEXT (2021) 
DOI: https://doi.org/10.47405/aswj.v6i2.164

\section{Conclusion}

The COVID-19 pandemic is causing significant risk to health and well-being. For the purpose of the risk mitigation, Japanese government asked the closure of all elementary schools, junior high schools and high schools nationwide, beginning March 2, 2020. At the same time, the government asked on people to stay-at -home and social distancing. Consequently, the school closures may have been prevented many covid-19 outbreaks and clusters among school children. Stay-at -home and social distancing may have been provided similar results, too.

In conclusion, we are not saying that COVID-19 policy responses such as school closures overall are ineffective for mitigating the COVID-19 pandemic in Japan. However, as we have seen, school closing policy is likely to have a negative impact on children's health and well-being such as increased risks of mental health, abuse and suicide. The important point is that these impacts is not the impact of COVID19 but the impact of the policy responses to COVID-19. The policy responses are likely to lead to a range of unexpected impacts and results. Therefore, policy makers, social workers and other professionals always should consider for the impact of policy responses to COVID-19 on children and adolescents.

\section{References}

Araújo, L.A., Veloso, C.F., Souza, M.C., Azevedo, J.M., Tarro, G. (2020). The potential impact of the COVID-19 pandemic on child growth and development: a systematic review. Jornal de Pediatr. https://doi.org/10.1016/j.jped.2020.08.008.

Asbury, K., Fox, L., Deniz, E., Code, A., Toseeb, (2020). U. How is COVID-19 affecting the mental health of children with special educational needs and disabilities and their families? PsyArXiv. https://doi. org/10.31234/osf.io/sevyd.

ASAHI SHIMBUN. (2020). Child abuse cases climb 10-20\% in Japan as families stay home more. ASAHI SHIMBUN, 12 May, 2020. http://www.asahi.com/ajw/articles/13367418.

Baron, E.J., Goldstein, E.G., Wallace, C.T. (2020). Suffering in silence: How COVID-19 school closures inhibit the reporting of child maltreatment. Journal of Public Economics, 190. https://doi.org/10.1016/j.jpubeco.2020.104258.

Campbell, A.M. (2020). An increasing risk of family violence during the Covid-19 pandemic: Strengthening community collaborations to save lives. Forensic Science International: Reports 2. http://doi.org/10.1016/j.fsir.2020.100089.

FAO Regional Office for Latin America and the Caribbean. (2020). FAO warns of the impact of COVID-19 on school feeding in Latin America and the Caribbean. http://www.fao.org/americas/noticias/ver/en/c/1266855/.

Fegert, J.M., Vitiello, B., Plener, P.L., Clemens, V. (2020). Challenges and burden of the Coronavirus 2019 (COVID-19) pandemic for child and adolescent mental health: a narrative review to highlight clinical and research needs in the acute phase and the long return to normality. Child and Adolescent Psychiatry and Mental, 14:20. https://doi.org/10.1186/s13034-020-00329-3.

Iwata, K., Doi, A., Miyakoshi, C. (2020). Was school closure effective in mitigating coronavirus disease 2019 (COVID-19)? Time series analysis using Bayesian inference. International Journal of Infectious Diseases, 99. https://doi.org/10.1016/j.ijid.2020.07.052.

Japan Times. (2021). School-age suicides in Japan hit record in 2020. Japan Times, 19 Feb, 2021. https://www.japantimes.co.jp/news/2021/02/16/national/social-issues/school-age-suicidesjapan-hit-record-2020/.

Japan Times. (2021). Japan starts examining impact of nationwide school closures. Japan Times, 6 Feb, 2021. https://www.japantimes.co.jp/news/2021/02/06/national/school-closures-survey/.

Lancet. (2020). Redefining vulnerability in the era of COVID-19. Lancet, VOLUME 395, ISSUE 10230, P1089. https://doi.org/10.1016/S0140-6736(20)30757-1.

Lawson, M., Piel, M.H., Simon, M. (2020). Child Maltreatment during the COVID-19 Pandemic: Consequences of Parental Job Loss on Psychological and Physical Abuse Towards Children. Child Abuse \& Neglect, 110. https://doi.org/10.1016/j.chiabu.2020.104709. 
DOI: https://doi.org/10.47405/aswj.v6i2.164

Lustig, N., Tommasi, M. (2020). Covid-19 and social protection of poor and vulnerable groups in Latin America: a conceptual framework. UNDP.

Ministry of Education, Culture, Sports, Science and Technology. (2021). Report on student suicide in Japan. https://www.mext.go.jp/content/20210216-mxt_jidou01-000012837_003.pdf.

National Center for Child Health and Development. (2020). National Online Survey of Children's Wellbeing During the COVID-19 Pandemic in Japan: Interim Report, Part 3. https://www.ncchd.go.jp/en/news/2020/20201102e.pdf.

National Center for Child Health and Development. (2021). National Online Survey of Children's Wellbeing During the COVID-19 Pandemic in Japan: Interim Report, Part 4. https://www.ncchd.go.jp/center/activity/covid19_kodomo/report/CxC4_finalrepo_20210210.pdf

Usami, M., Sasaki, S., Sunakawa, H., Toguchi, Y., Tanese, S., Saito, K., ․ Mizumoto, Y. (2021). Care for children's mental health during the COVID-19 pandemic in Japan. Global Health \& Medicine. https://doi.org/10.35772/ghm.2020.01081.

United Nations Economic Commission for Africa. (2015). Socio-economic Impacts of the Ebola Virus Disease on Africa.

Witt, A., Ordóñez, A., Martin, A., Vitiello, B., Fegert, J.M. (2020). Child and adolescent mental health service provision and research during the Covid-19 pandemic: challenges, opportunities, and a call for submission. Child and Adolescent Psychiatry and Mental, 14:19. https://doi.org/10.1186/s13034-020-00324-8. 